dezembro, uma sessão de encerramento informal do Ano Internacional da Química da Universidade de Évora designada por "Ano Internacional da Química 2011 ... 12 meses depois".

\section{Programa:}

17:15 - Balanço do Ano Internacional da Química 2011

- Professor Doutor Jorge Carreira Gonçalves Calado, Presidente da Comissão Nacional do AIQ 2011 / Centenário da Sociedade Portuguesa de Química
- Comissão do CQE/DQUI da Escola de Ciências e Tecnologia da Universidade de Évora para o AIQ 2011

17:30 - Tertúlia "Química e Sociedade"

- "Haja luz! Uma história da química através de tudo", Professor Doutor Jorge Carreira Gonçalves Calado

18:45 - Quinteto de Violinos

- Allegretto: Michael Jacques; The Mirror: W.A. Mozart; Tingly Loup: Peter Maxwell Davies; Canon: J. Pachelbel; Four Seasons - Spring: A. Vivaldi; Sonata n.10: A. Corelli
Interpretação: Carla Lourenço, Catarina Vicente, David Batista, Marta Dias, Joana Barreiros

19:00 - Sessão de autógrafos

- Livro "Haja luz! Uma história da química através de tudo" pelo Professor Doutor Jorge Carreira Gonçalves Calado

LIVRos E PuBLICAÇõES:

Newsletters mensal SPQ e quinzenal AIQ

Vanda Capitolino (quimica2011@spq.pt) www.spq.pt/quimica2011

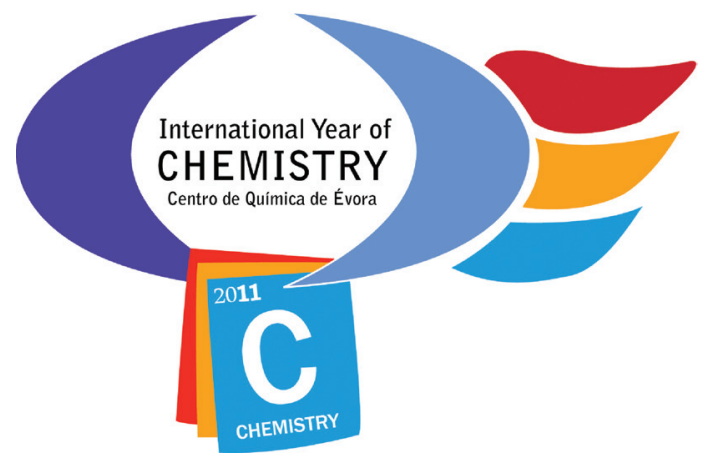

\title{
Concurso CSI - Compreender, Saber, INVESTIGAR A QUÍMICA
}

No âmbito das atividades comemorativas do Ano Internacional da Química 2011, o Centro de Química de Évora e o Departamento de Química da Escola de Ciências e Tecnologia da Universidade de Évora promoveram o "Concurso CSI - Compreender, Saber, Investigar a Química”. Esta iniciativa teve como objetivos principais fomentar o interesse pela Química, estimular o espírito de iniciativa, criatividade e literacia científica dos alunos, bem como demonstrar a importância da Química na satisfação das necessidades da Sociedade Moderna e no bem-estar da Humanidade.

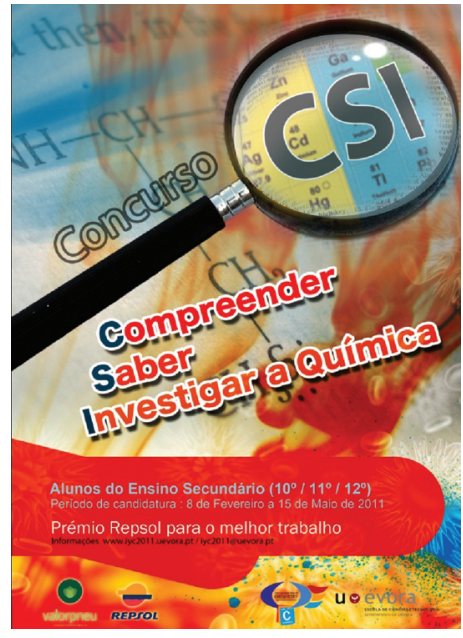

O CSI contou com a participação de uma centena de alunos provenientes de 16 escolas secundárias pertencentes aos distritos de Bragança, Aveiro, Porto, Lisboa, Castelo Branco, Santarém e Évora. Dos 35 trabalhos concorrentes destacaram-se "Sabão de Inverno - A Química na Proteção do Ambiente" e "Química e Arte" vencedores, respetivamente, do Prémio Repsol para o melhor trabalho, i-pads, e da menção honrosa Repsol, i-pod. A Professora responsável pelo projeto “Sabão de Inverno", Margarida Duarte da Escola Secundária de Azambuja (Santarém), referiu que o facto dos índios da Amazónia lavarem os seus utensílios fazendo uma mistura de sebo de animal com cinzas das fogueiras e das pessoas do campo, antigamente, arearem os tachos e panelas com cinzas das lareiras para ficarem brilhantes despertou a curiosidade e levou-os a investigar....

A investigação no laboratório, realizada pelas alunas Maria Vieira, Carolina Marques, Tiago Caria, Andreia Firmino e Rita Narciso, consistiu em apurar as "receitas" de sabão duro e sabão líquido, substituindo gradualmente o hidróxido de sódio por "água de cinzas". As cinzas, por terem uma percentagem elevada de ião potássio permitem obter um sabão mais macio e com boas qualidades de lavagem. Depois de fervidas e coadas, as cinzas são devolvidas ao solo (no jardim da escola) pois, como já não apresentam o caráter alcalino inicial, são inofensivas para as plantas. Todos os recipientes utilizados no fabrico do Sabão de Inverno são reutilizados: baldes de tinta para a massa de sabão; pacotes de leite para as formas; garrafas de água para embalagem do sabão líquido.

Este projeto envolveu não só a escola, como a comunidade, doando óleo usado, cinzas e embalagens e, no final, todos receberam Sabão de Inverno. Segundo o júri do concurso, constituído por Professores do Departamento de Química e Membros do Centro de Química de Évora, a escolha do trabalho vencedor resulta da originalidade e relevância social do conceito apresentado, a forma inteligente como foi desenvolvido o trabalho e o esforço despendido para um resultado final harmonioso, onde ressalta uma bela ilustração do método científico. O trabalho promoveu o 

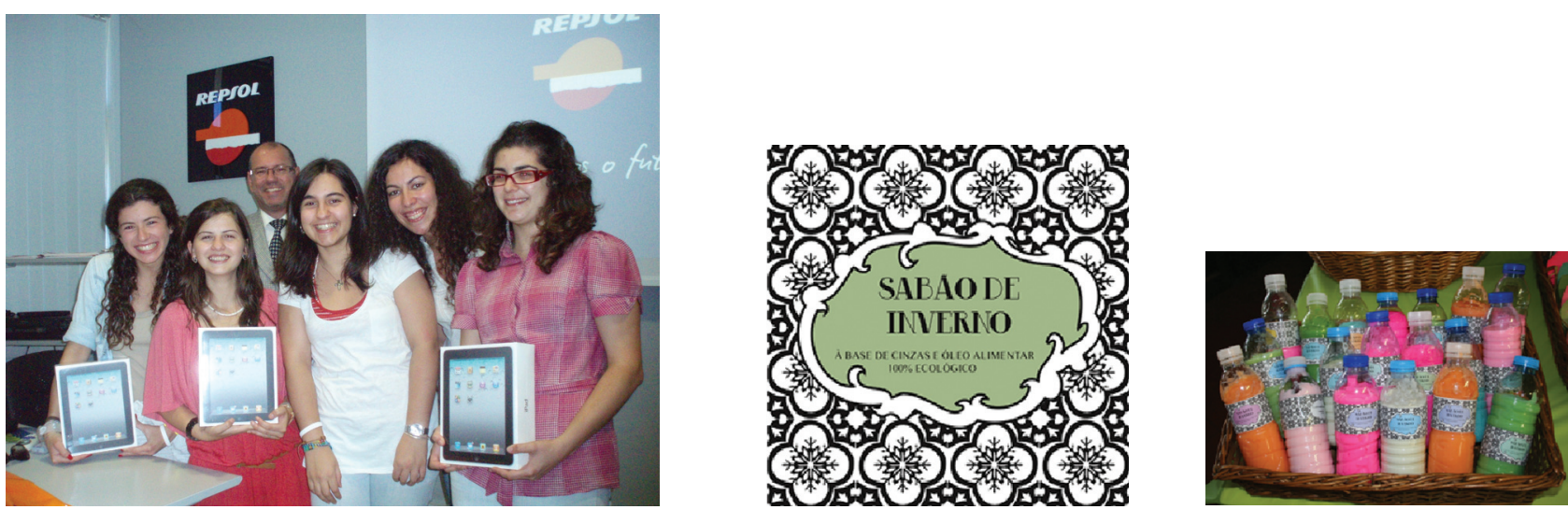

Grupo vencedor do concurso CSI e responsável pelo Prémio Repsol

contacto com a realidade extraescolar e a valorização dos conhecimentos e das vivências da comunidade local. As preocupações ambientais revelam-se através da reciclagem/ reutilização de resíduos domésticos conducentes à obtenção de produtos com aplicação prática quotidiana. A menção honrosa Repsol foi atribuída a Bernardo Dias, aluno do Colé- gio Cedros (Vila Nova de Gaia), que desenvolveu, sob orientação do Professor Nuno Francisco, um pequeno filme sobre o tema "Química e Arte". De acordo com o júri, esta menção justifica-se pela originalidade e qualidade da abordagem ao tema, pelo equilíbrio entre forma e conteúdo e pela beleza intrínseca da peça, que faz dela um agradável documentário.
A peça manifesta uma preocupação cuidada com todos os pormenores e permite redescobrir a importância da química na vertente da Arte, constituindo-se ela própria uma agradável obra artística.

Cristina Galacho e Paulo Mendes

(iyc2011@uevora.pt) Comissão do CQE|DQUI da ECTUE para o AIQ2011

\section{Cerimónia de Abertura da Continuação do Ano InTERnACIONAL dA QuímicA}

O título, à primeira vista, pode parecer pouco convencional, mas estas foram as palavras oficiais usadas para qualificar o encerramento do Ano Internacional da Química, proferidas na cerimónia organizada em Bruxelas, no dia 1 de dezembro de 2011, pelo Representante da UNESCO que agradeceu o fantástico envolvimento da IUPAC, das Sociedades de Química dos países-membros, das Academias de Ciência, da Indústria, dos Jovens Líderes e dos inúmeros jovens que, por todo o mundo, participaram na Experiência Global. É particularmente significativo que o evento tenha sido patrocinado também por grandes nomes da Indústria Química, como SOLVAY, CEFIC, DU PONT, BASF, DOW, TOTAL, GSK, entre outros.

Numa cerimónia que foi presidida pelo Príncipe Philippe da Bélgica, a Presidente da IUPAC, Prof. Nicole Moreau, apresentou uma breve retrospetiva de alguns acontecimentos que foram autênticas pedras angulares do Ano Internacional da Química 2011, desde o pequeno-almoço das mulheres "Sharing a Chemical Moment”, passando pela cerimónia oficial de abertura, a 27 e 28 de janeiro, em Paris, pela cerimónia de lançamento da Experiência Global, em 22 de março, em Cape Town, pela edição de selos comemorativos, pela celebração do centenário da atribuição do Prémio Nobel da Química a Marie Sklodovska Curie e pela descoberta de dois novos elementos, de números atómicos 114 e 116 cujos nomes e símbolos aguardam aprovação formal pela IUPAC e pela IUPAP, mas previsivelmente FI (em homenagem ao físico russo Georgy Flerov) e Lv (em homenagem ao Laboratório Lawrence Livermore dos Estados Unidos da América), respetivamente. Fica-lhe a preocupação de que talvez se tenha falado mais para os químicos que para o público em geral. A paixão que os químicos evidenciam por esta ciência apaixonante, tem que transparecer para o exterior e dar frutos.

O Programa da sessão incluiu a apresentação de um projeto conduzido por uma equipa internacional de 12 Jovens Líderes selecionados de entre os quadros das várias empresas industriais patrocinadoras, a quem foi pedido que imaginassem a sua carreira profissional nas próximas décadas e nos relatassem as suas expectativas sobre o papel das Ciências da Vida, nomeadamente da Química, da Indústrias, dos Governos para um mundo melhor em 2050. É com algum orgulho que refiro que dois dos doze Jovens Líderes, são de língua portuguesa, a portuguesa Jacqueline Dias, da GSK Biologicals, e o brasileiro Rui Vogt Alves da Cruz, da Dow Chemical Company, que liderou os Jovens Líderes. O grupo selecionou a descoberta da penicilina e o tratamento da água de abastecimento público como marcos históricos importantes, que foram decisivos no aumento da esperança de vida de que usufruímos. Defendeu uma forte aposta na educação e na formação multidisciplinar, exortou à colaboração de governos, indústria, universidades e institutos de investigação, elegendo como prioridades para o futuro de qualquer simples ser humano "Comida, Saúde, Felicidade"! Seguiu-se uma mesa redonda em que um painel convidado do qual fazia parte a Prémio Nobel da Química 2009, Prof. Ada Yonath, discutiu as 